\title{
Quantitative analysis of cell-free DNA in ovarian cancer
}

\author{
XUEFENG SHAO ${ }^{1 *}$, YAN HE $^{2 *}, \mathrm{MIN} \mathrm{JI}^{3}$, XIAOFANG CHEN $^{4}, \mathrm{JING} \mathrm{QI}^{5}$, \\ WEI SHI ${ }^{5}$, TIANBO HAO 5 and SHAOQING JU ${ }^{5}$ \\ ${ }^{1}$ Department of Clinical Laboratory, Maternity and Child Healthcare Hospital of Nantong, Nantong, Jiangsu 226018; \\ ${ }^{2}$ Department of Gynecology, The First Affiliated Hospital of Xinjiang Medical University, Urumqi, Xinjiang 830000; \\ Departments of ${ }^{3}$ Internal Medicine and ${ }^{4}$ Gynecology, Maternity and Child Healthcare Hospital of Nantong, Nantong, \\ Jiangsu 226018; ${ }^{5}$ Department of Laboratory of Surgery, Affiliated Hospital of Nantong University, \\ Nantong, Jiangsu 226018, P.R. China
}

Received October 28, 2014; Accepted August 17, 2015

DOI: $10.3892 / 01.2015 .3771$

\begin{abstract}
The aim of the present study was to investigate the association between cell-free DNA (cf-DNA) levels and clinicopathological characteristics of patients with ovarian cancer using a branched DNA (bDNA) technique, and to determine the value of quantitative cf-DNA detection in assisting with the diagnosis of ovarian cancer. Serum specimens were collected from 36 patients with ovarian cancer on days 1, 3 and 7 following surgery, and additional serum samples were also collected from 22 benign ovarian tumor cases, and 19 healthy, non-cancerous ovaries. bDNA techniques were used to detect serum cf-DNA concentrations. All data were analyzed using SPSS version 18.0. The cf-DNA levels were significantly increased in the ovarian cancer group compared with those of the benign ovarian tumor group and healthy ovarian group $(\mathrm{P}<0.01)$. Furthermore, cf-DNA levels were significantly increased in stage III and IV ovarian cancer compared with those of stages I and II $(\mathrm{P}<0.01)$. In addition, cf-DNA levels were significantly increased on the first day post-surgery $(\mathrm{P}<0.01)$, and subsequently demonstrated a gradual decrease. In the ovarian cancer group, the area under the receiver operating characteristic curve of cf-DNA and the sensitivity were 0.917 and $88.9 \%$, respectively, which was higher than those of cancer antigen $125(0.724,75 \%)$ and human epididymis protein $4(0.743,80.6 \%)$. There was a correlation between the levels of serum cf-DNA and the occurrence and development of ovarian cancer in the patients evaluated. bDNA techniques possessed higher sensitivity and specificity
\end{abstract}

Correspondence to: Dr Shaoqing Ju, Department of Laboratory of Surgery, Affiliated Hospital of Nantong University, 20 Xisi Road, Nantong, Jiangsu 226018, P.R. China

E-mail: shaoqingjucn@126.com

*Contributed equally

Key words: ovarian cancer, cell free DNA, branched DNA, tumor marker than other methods for the detection of serum cf-DNA in patients exhibiting ovarian cancer, and bDNA techniques are more useful for detecting cf-DNA than other factors. Thus, the present study demonstrated the potential value for the use of bDNA as an adjuvant diagnostic method for ovarian cancer.

\section{Introduction}

Ovarian cancer is one of the most common malignant tumors of the female reproductive system, and is the third most frequently occurring cancer in women, following cervical and endometrial cancer (1). Ovarian cancer possesses the poorest prognosis of all gynecological tumors, and is typically undetectable at onset (2). Thus, the majority of patients are diagnosed at advanced stages, resulting in a high rate of mortality. Therefore, ovarian cancer is a significant threat to female health (3). Due to the fact that patients with ovarian cancer exhibit no symptoms during the early stages, as well as a lack of effective screening measures, $>80 \%$ patients with ovarian cancer are diagnosed at an advanced stage (4). These patients possess a five-year survival rate of just 20-30\%; however, the five-year survival rate of patients with ovarian cancer diagnosed at an early stage is $>90 \%$ (5). Therefore, early diagnosis is significant for the prognosis of patients with ovarian cancer. At present, certain tumor markers, including cancer antigen 125 (CA125) and human epididymis protein 4 (HE-4), aid in the early diagnosis of ovarian cancer (6,7). Furthermore, these markers are significant for monitoring the development and progression of ovarian cancer. However, there are various associated disadvantages, including, high false-positive or -negative rates and low specificity (7). In order to improve the accuracy of diagnosis for ovarian cancer, the use of cooperative detection methods may be required.

Since Leon et al (8) identified cell-free DNA (cf-DNA) in the serum of cancer patients in 1977, cf-DNA has presented a number of advantages in the early stages of tumor diagnosis $(9,10)$, particularly in solid tumors (11). Previous studies of cf-DNA have included qualitative and quantitative investigation. Qualitative analysis primarily detects tumor-specific gene alterations $(12,13)$, including gene mutations, promoter hypermethylation of tumor suppressor genes (14) and microsatellite 
alterations (15). Quantitative analyses primarily involve radioimmunity methods (16), polymerase chain reaction (PCR) amplification techniques (17), DNA nick translation labeling techniques (18) and DNA DipStick kits (19). These methods are associated with a number of issues, including radioactivity, environmental pollution problems, complex instructions and DNA loss during the process itself, which result in reduced sensitivity.

Branched DNA (bDNA), in contrast to PCR (which amplifies a portion of the gene sequence), is a signal amplification technology that detects the presence of specific nucleic acids by measuring the signal generated by specific hybridization of numerous branched, labeled DNA probes on an immobilized target nucleic acid (20).

The present study utilized a bDNA technique in order to quantitatively detect the levels of cf-DNA in patients exhibiting ovarian cancer, and analyzed the association between cf-DNA levels and clinicopathological characteristics, in order to investigate the value of cf-DNA in the diagnosis of ovarian cancer by quantitative measures.

\section{Patients and methods}

Patients. Samples were obtained from 36 patients exhibiting ovarian cancerfrom the Maternity and Child Healthcare Hospital of Nantong and the Tumor Hospital of Nantong (Nantong, China) between October 2011 and October 2012. The average age of patients exhibiting ovarian cancer was 58.6 years (range, 40-85 years) and all diagnoses were confirmed via pathological examination. Tumor staging was performed according to the International Federation of Gynecology and Obstetrics (FIGO) criteria (2010) (21). In addition, samples from 29 healthy women served as the control group, and the average age of these patients was 57.7 years (range, $42-75$ years). A total of 22 cases of benign ovarian tumor were also investigated, and the average age of these patients was 51.6 years (range, $37-72$ years). All diagnoses were confirmed by surgical and pathological examination. The present study was conducted in accordance with the Declaration of Helsinki, and was approved by the Ethics Committee of the Maternity and Child Healthcare Hospital of Nantong (Nantong, China). Written informed consent was obtained from all participants.

Specimen collection. Venous blood $(5 \mathrm{ml})$ was collected from patients with ovarian cancer and benign tumors, and healthy women, on an empty stomach in the morning. The blood specimens were collected in tubes, and subsequently centrifuged at $2,800 \mathrm{x} \mathrm{g}$ and $4^{\circ} \mathrm{C}$ for $15 \mathrm{~min}$. The serum was transferred into Eppendorf tubes (Eppendorf, Hamburg, Germany) and stored at $-80^{\circ} \mathrm{C}$.

cf-DNA detection using a bDNA technique. Specimens were diluted with distilled water (dilution, 1:20), heated at $95^{\circ} \mathrm{C}$ for 5 min and subsequently placed rapidly into cold water. A preparation solution $(90 \mu \mathrm{l})$ containing $33.0 \mu \mathrm{l}$ lysate, $55.3 \mu \mathrm{l}$ Tris-EDTA buffer solution, $0.1 \mu \mathrm{l}$ proteinase $\mathrm{K}, 1.0 \mu \mathrm{l}$ confining liquid, $0.3 \mu \mathrm{l}$ capture extender probe, $0.3 \mu \mathrm{l}$ label extender probe and $10 \mu \mathrm{l}$ DNA samples, including samples, double controls and three standards, was added into 96-well plates, and subsequently blocked using tin foil papers. All aforementioned reagents were provided by Fuzhou Maixin Biotechnology Development Co., Ltd., (Fuzhou, China). Plates were immediately placed in the HB-1000 hybridization oven (Nanjing Xincheng Health Biotech Co., Ltd., Nanjing, China) and hybridized at $55^{\circ} \mathrm{C}$ for $16-21 \mathrm{~h}$. Subsequently, each well was washed three times with $300 \mu \mathrm{l}$ scrubbing solution (Fuzhou Maixin Biotechnology Development Co., Ltd.), followed by addition of $100 \mu$ l labeling probe (dilution, 1:1,000) and incubation at $55^{\circ} \mathrm{C}$ for $60 \mathrm{~min}$. This process was repeated once. Subsequently, $100 \mu \mathrm{l}$ working solution (Fuzhou Maixin Biotechnology Development Co., Ltd.) was added to each well following washing, and plates were incubated at room temperature for 5-10 min. Finally, 96-well plates were placed in the LMax microtiter plate luminometer (MaxLine Inc., CA, USA); absorbance values (A) were acquired, and the mean absorbance value was calculated. cf-DNA standard curves were constructed based on standard concentrations and A values. cf-DNA levels were calculated using the standard curves.

CA125 and HE-4 detection. CA125 and HE-4 levels were detected using the Roche E170 chemiluminescence detector (Roche Diagnostics, Indianapolis, IN, USA), and CA125 and HE-4 kits (Shanghai Sangon Biological Engineering Co., Ltd., Shanghai, China), according to the manufacturer's instructions.

Statistical analysis. Statistical analysis was performed using SPSS version 18.0 (SPSS Inc., Chicago, IL, USA). Measured data are expressed as the mean \pm standard deviation. Serum cf-DNA levels are presented as a skew distribution: Median (25 ${ }^{\text {th }}$ percentile- $75^{\text {th }}$ percentile) $\left[\mathrm{M}\left(\mathrm{P}_{25}-\mathrm{P}_{75}\right)\right]$, following a test of normality. The Mann-Whitney $U$ test was utilized for comparisons between two groups and the Spearman's rank order correlation was utilized to analyze double variable correlations. Receiver operating characteristic (ROC) curves and the area under the ROC curves (AUC) were utilized to evaluate the sensitivity and specificity of ovarian cancer detection. $\mathrm{P}<0.05$ was considered to indicate a statistically significant difference.

\section{Results}

Serum levels of $c f$-DNA are significantly increased in ovarian cancer. The serum levels of cf-DNA were 197.176 (94.757-303.367), 199.943 (78.730-396.208) and 811.354 (450.714-1307.185) $\mu \mathrm{g} / \mathrm{l}$ in the healthy control, benign tumor and ovarian cancer groups, respectively (Table I).

According to the Mann-Whitney U test, the serum levels of cf-DNA were significantly increased in the ovarian cancer group compared with those of the healthy control and benign tumor groups $(\mathrm{P}<0.01)$. There was no significant difference between the benign tumor group and control group $(\mathrm{P}=0.917)$. Furthermore, according to FIGO staging of ovarian cancer, the serum cf-DNA levels of stage I-II ovarian cancer were significantly different from those observed in stage III and IV $(\mathrm{P}<0.01)$, although there was no significant difference between stage III and stage IV $(\mathrm{P}=0.610)$.

No association is identifiable between the serum levels of $c f$-DNA and clinicopathological features. No statistically significant differences were observed between cf-DNA levels 
Table I. Comparison of the serum levels of cf-DNA.

\begin{tabular}{|c|c|c|c|}
\hline Clinicopathological parameter & $\mathrm{n}$ & cf-DNA level, $\mu \mathrm{g} / 1\left[\mathrm{M}\left(\mathrm{P}_{25}-\mathrm{P}_{75}\right)\right]$ & P-value \\
\hline \multicolumn{4}{|l|}{ Group } \\
\hline Control & 19 & $197.176(102.600-303.367)$ & \\
\hline Benign tumor & 22 & 199.943 (78.730-396.208) & \\
\hline Ovarian cancer & 36 & 881.181 (624.110-1409.170) & $<0.001^{\mathrm{a}}$ \\
\hline \multicolumn{4}{|l|}{ FIGO stage } \\
\hline I-II & 11 & 593.401 (349.743-737.295) & $<0.001^{\mathrm{b}}$ \\
\hline III & 16 & 1104.975 (829.756-1805.888) & $0.610^{\mathrm{c}}$ \\
\hline IV & 9 & $954.370(411.354-1507.910)$ & \\
\hline
\end{tabular}

${ }^{\mathrm{a}} \mathrm{P}<0.01$, ovarian cancer group vs. control group and ovarian cancer group vs. benign tumor group; ${ }^{\mathrm{b}} \mathrm{P}<0.01$, stage I-II vs. stage III and stage I-II vs. stage IV; ${ }^{c} \mathrm{P}=0.610$, stage III vs. stage IV. cf-DNA, cell-free DNA; FIGO, International Federation of Gynecology and Obstetrics.

Table II. Comparison of cf-DNA levels among various clinicopathological parameters in patients with ovarian cancer.

\begin{tabular}{|c|c|c|c|}
\hline Clinicopathological parameter & $\mathrm{n}$ & cf-DNA level, $\mu \mathrm{g} / 1\left[\mathrm{M}\left(\mathrm{P}_{25}-\mathrm{P}_{75}\right)\right]$ & P-value \\
\hline Age, years & & & 0.928 \\
\hline$<60$ & 19 & $646.757(326.429-1034.856)$ & \\
\hline$\geq 60$ & 17 & $953.347(477.989-1527.393)$ & \\
\hline Degree of differentiation & & & 0.785 \\
\hline High & 10 & $800.951(429.309-1411.844)$ & \\
\hline Moderate & 15 & $865.411(343.617-1243.754)$ & \\
\hline Low & 11 & $729.056(452.638-1461.874)$ & \\
\hline Complications & & & 0.689 \\
\hline Yes & 15 & $908.910(593.401-1507.910)$ & \\
\hline No & 21 & $971.621(642.051-1526.560)$ & \\
\hline Tumor type & & & 0.824 \\
\hline Endometrioid adenocarcinoma of ovary & 14 & $727.152(129.725-1216.922)$ & \\
\hline Ovarian serous adenocarcinoma & 22 & $811.354(467.924-1471.326)$ & \\
\hline
\end{tabular}

Table III. Alterations in cf-DNA level prior to and following surgery.

\begin{tabular}{lcr}
\hline Time-point & cf-DNA level, $\mu \mathrm{g} / 1\left[\mathrm{M}\left(\mathrm{P}_{25}-\mathrm{P}_{75}\right)\right]$ & $\mathrm{P}-\mathrm{value}$ \\
\hline Pre-operation & $881.181(624.110-1409.170)$ & $0.001^{\mathrm{a}}$ \\
Postoperative day 1 & $1531.718(929.120-3271.500)$ & $0.444^{\mathrm{b}}$ \\
Postoperative day 3 & $1386.810(914.410-2595.596)$ & $0.002^{\mathrm{c}}$ \\
Postoperative day 7 & $914.410(93.401-1507.910)$ & \\
\hline
\end{tabular}

${ }^{\mathrm{a}} \mathrm{P}<0.01$, vs. pre-operation; ${ }^{\mathrm{b}} \mathrm{P}=0.444$, vs. postoperative day 1 ; ${ }^{\mathrm{c}} \mathrm{P}=0.002$, vs. postoperative day 3 .

and age, differentiation, tumor classification and complications among the ovarian cancer, healthy control or benign tumor groups (Table II).

cf-DNA levels increase following surgery and, subsequently, gradually decrease. Postoperative cf-DNA levels were significantly increased in patients exhibiting ovarian cancer, these levels then gradually decreased. This may potentially be due to surgical trauma causing cells to enter the bloodstream and generate significant quantities of cf-DNA. Following metabolism of this increased cf-DNA, cf-DNA levels are able to decrease (Table III). 
Table IV. Efficacy comparison between cf-DNA, CA125 and HE-4 levels.

\begin{tabular}{lccccrr}
\hline Index & AUC & Baseline & Sensitivity, $\%$ & Specificity, $\%$ & $95 \%$ CI & P-value \\
\hline cf-DNA & 0.917 & 478.435 & 88.9 & 89.5 & $0.842-0.991$ & $<0.001$ \\
CA125 & 0.724 & 33.745 & 75.0 & 50.6 & 68.4 & $0.592-0.855$ \\
HE-4 & 0.743 & 137.627 & $0.605-0.881$ & 0.003
\end{tabular}

cf-DNA, cell free DNA; CA125, cancer antigen 125; HE-4, human epididymis protein 4; AUC, area under curve; CI, confidence interval.

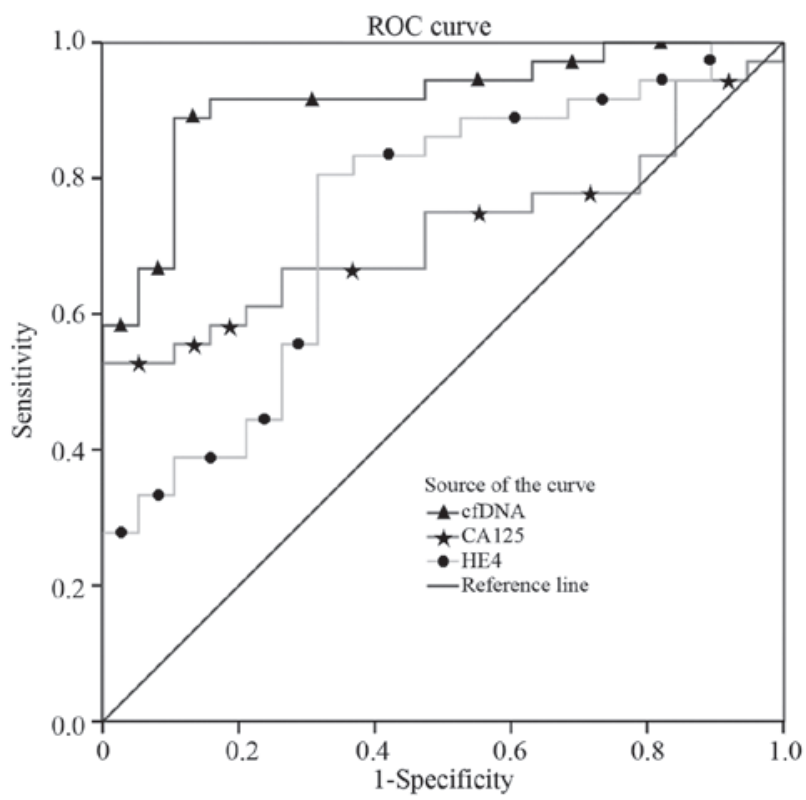

Figure 1. ROC curves of cf-DNA, CA125 and HE-4. cf-DNA, cell-free DNA; CA125, cancer antigen 125; HE-4, human epididymis protein 4; ROC, receiver operating characteristic.

There is no correlation between the serum levels of cf-DNA and CA125 and HE-4. Spearman correlation analysis demonstarted that the correlation coefficient between cf-DNA and CA125 was $0.060(\mathrm{P}=0.729)$, and the correlation coefficient between cf-DNA and HE-4 was $0.043(\mathrm{P}=0.802)$. This indicated that there was no significant difference in the level of correlation between these factors and cf-DNA.

According to the ROC curve (Fig. 1), the cut-off values for cf-DNA, CA125 and HE-4 were $478.435 \mu \mathrm{g} / 1,33.745 \mathrm{U} / \mathrm{ml}$ and $137.627 \mathrm{pmol} / \mathrm{l}$, respectively. Furthermore, the AUC, sensitivity and specificity of cf-DNA in the ovarian cancer group were $0.917,88.9 \%$ and $89.5 \%$, respectively, which were higher than those of CA125 (0.724, 75\% and 52.6\%) and HE-4 (0.743, $80.6 \%$ and $68.4 \%$ ) (Table IV). cf-DNA levels combined with CA125 and HE-4 detection may improve the sensitivity and specificity of ovarian cancer detection. When two or three of these biomarkers were identified as positive during combined detection, the sensitivity and specificity were $91.67 \%(33 / 36)$ and $84.21 \%(16 / 19)$ respectively.

\section{Discussion}

Due to developments in tumor cellular and molecular biology, there has been increased interest in serum cf-DNA as a potential biomarker in oncology $(10,22)$. cf-DNA alteration, as a tumor indicator, has been observed in the serum of patients with certain tumors, and cf-DNA alteration has been associated with the expression of certain genes in tumor tissue (23). As described in the Introduction, existing qualitative and quantitative methods exhibit a number of limitations (12-19). By contrast, bDNA techniques may be regarded as an improvement compared with other monitoring methods associated with existing tumor markers, due to their convenience and lack of invasiveness (24). The present study used bDNA techniques to detect the levels of cf-DNA in patients exhibiting ovarian cancer. The associations between cf-DNA levels and clinicopathological characteristics were analyzed, and the value of cf-DNA in the diagnosis of ovarian cancer was investigated.

Generally, cf-DNA is maintained at low and constant levels in normal human serum, and is significantly increased in patients exhibiting certain tumors. A previous study demonstrated that serum cf-DNA levels are directly associated with the presence, development, recovery from and recurrence of malignant tumors (25). In the present study, healthy volunteers, patients with benign ovarian tumors and patients exhibiting ovarian cancer were compared, and the results indicated that the serum cf-DNA levels were significantly increased in the ovarian cancer group compared with those of the control group $(\mathrm{P}<0.01)$. However, there was no significant difference between those of the benign tumor and healthy control groups $(\mathrm{P}>0.05)$. Furthermore, according to FIGO staging, the serum levels of cf-DNA were significantly increased in patients with stage III and IV ovarian cancer compared with stage I-II patients $(\mathrm{P}<0.01)$. cf-DNA levels were also significantly increased following surgery $(\mathrm{P}<0.01)$, and then decreased gradually; there was no significant difference observed between pre-operative and postoperative day $7 \mathrm{cf}-\mathrm{DNA}$ levels $(\mathrm{P}>0.05)$. The results of the present study suggested that the serum levels of cf-DNA increased gradually with the development of disease, and monitoring the serum levels of cf-DNA may aid in the analysis of patient status, prognosis and efficacy observations. Serum CA125 and HE-4 are common markers of ovarian cancer and possess diagnostic value; however, their sensitivity and specificity have been observed to be lower than that of the cf-DNA assay. According to Spearman's related analysis, cf-DNA levels did not correlate with CA125 and HE-4 levels, which indicated that cf-DNA was an independent prognostic biomarker due to alternative pharmacokinetics (26).

ROC curves of cf-DNA revealed that the sensitivity and specificity of serum cf-DNA levels were 88.9 and $89.5 \%$, respectively, while the baseline was $478.435 \mu \mathrm{g} / 1$ as diagnosed for ovarian cancer, which were higher than those of CA125 and 
HE-4. Furthermore, the AUC of the ROC curves of cf-DNA, CA125 and HE-4 were $0.917,0.724$ and 0.743 , respectively; therefore, cf-DNA combined with CA125 and HE-4 detection may improve sensitivity up to $91.67 \%$.

In conclusion, the serum levels of cf-DNA were significantly increased in patients exhibiting ovarian cancer, compared with those of patients with benign ovarian tumors and healthy controls. Furthermore, cf-DNA levels were observed to increase as ovarian cancer progressed to later disease stages. Thus, quantitative detection of cf-DNA may possess value for the diagnosis of ovarian cancer, and bDNA techniques demonstrated higher sensitivity and specificity for detecting serum cf-DNA levels compared with existing methods.

\section{Acknowledgements}

The present study was supported by the National Natural Science Foundation of China (grant no. 81000775/H2006), the Social Development Foundation of Nantong City (grant no. S2010021), the Technology Innovation and Demonstration Program of Nantong City (grant no. S2011025) and the Medical Innovation Team and Leader Program of Jiangsu Province (grant no. LJj201133).

\section{References}

1. Bhurgri Y, Shaheen Y, Kayani N, Nazir K, Ahmed R, Usman A, Bashir I, Setna F, Bhurgri A, Hasan SH and Zaidi SM: Incidence, trends and morphology of ovarian cancer in Karachi (1995-2002). Asian Pac J Cancer Prev 12: 1567-1571, 2011.

2. Tinelli A, Vergara D, Martignago R, Leo G, Pisanò $M$ and Malvasi A: An outlook on ovarian cancer and borderline ovarian tumors: Focus on genomic and proteomic findings. Curr Genomics 10: 240-249, 2009.

3. Sharifian A, Pourhoseingholi MA, Norouzinia M and Vahedi M: Ovarian cancer in Iranian women, a trend analysis of mortality and incidence. Asian Pac J Cancer Prev 15: 10787-10790, 2014.

4. Ohman AW, Hasan N and Dinulescu DM: Advances in tumor screening, imaging, and avatar technologies for high-grade serous ovarian cancer. Front Oncol 4: 322, 2014.

5. Kajiyama H, Shibata K, Mizuno M, Umezu T, Suzuki S, Nawa A, Kawai M, Nagasaka T and Kikkawa F: Long-term survival of young women receiving fertility-sparing surgery for ovarian cancer in comparison with those undergoing radical surgery. Br J Cancer 105: 1288-1294, 2011.

6. Zhen S, Bian LH, Chang LL and Gao X: Comparison of serum human epididymis protein 4 and carbohydrate antigen 125 as markers in ovarian cancer: A meta-analysis. Mol Clin Oncol 2: 559-566, 2014.

7. Karlan BY, Thorpe J, Watabayashi K, Drescher CW, Palomares M, Daly MB, Paley P, Hillard P, Andersen MR, Anderson G, et al: Use of CA125 and HE4 serum markers to predict ovarian cancer in elevated-risk women. Cancer Epidemiol Biomarkers Prev 23: 1383-1393, 2014.

8. Leon SA, Shapiro B, Sklaroff DM and Yaros MJ: Free DNA in the serum of cancer patients and the effect of therapy. Cancer Res 37: 646-650, 1977.

9. Salani R, Davidson B, Fiegl M, Marth C, Müller-Holzner E, Gastl G, Huang HY, Hsiao JC, Lin HS, Wang TL, et al: Measurement of cyclin E genomic copy number and strand length in cell-free DNA distinguish malignant versus benign effusions. Clin Cancer Res 13: 5805-5809, 2007.
10. Fox BP and Kandpal RP: DNA-based assay for EPHB6 expression in breast carcinoma cells as a potential diagnostic test for detecting tumor cells in circulation. Cancer Genomics Proteomics 7: 9-16, 2010.

11. Esposito A, Bardelli A, Criscitiello C, Colombo N, Gelao L, Fumagalli L, Minchella I, Locatelli M, Goldhirsch A and Curigliano G: Monitoring tumor-derived cell-free DNA in patients with solid tumors: Clinical perspectives and research opportunities. Cancer Treat Rev 40: 648-655, 2014.

12. Zhang Q, Hu G, Yang Q, Dong R, Xie X, Ma D, Shen K and Kong B: A multiplex methylation-specific PCR assay for the detection of early-stage ovarian cancer using cell-free serum DNA. Gynecol Oncol 130: 132-139, 2013.

13. Manderson EN, Presneau N, Provencher D, Mes-Masson AM and Tonin PN: Comparative analysis of loss of heterozygosity of specific chromosome $3,13,17$, and X loci and TP53 mutations in human epithelial ovarian cancer. Mol Carcinog 34: 78-90, 2002.

14. Tian F, Yip SP, Kwong DL, Lin Z, Yang Z and Wu VW: Promoter hypermethylation of tumor suppressor genes in serum as potential biomarker for the diagnosis of nasopharyngeal carcinoma. Cancer Epidemiol 37: 708-713, 2013.

15. Carpagnano GE, Costantino E, Palladino GP, Lacedonia D, Martinelli D, Orlando S and Foschino-Barbaro MP: Microsatellite alterations and cell-free DNA analysis: Could they increase the cytology sensitivity in the diagnosis of malignant pleural effusion? Rejuvenation Res 15: 265-273, 2012.

16. Portincasa P, Conti G and Chezzi C: Radio immune Western blotting: A possible solution to indeterminate conventional Western blotting results for the serodiagnosis of HIV infections. New Microbiol 19: 85-90, 1996.

17. Wong IH: Qualitative and quantitative polymerase chain reaction-based methods for DNA methylation analyses. Methods Mol Biol 336: 33-43, 2006.

18. Maehara Y, Anai H, Kusumoto T, Sakaguchi Y and Sugimachi K: Nick translation detection in situ of cellular DNA strand break induced by radiation. Am J Pathol 134: 7-10, 1989.

19. Kalogianni DP, Litos IK, Christopoulos TK and Ioannou PC: Dipstick-type biosensor for visual detection of DNA with oligonucleotide-decorated colored polystyrene microspheres as reporters. Biosens Bioelectron 24: 1811-1815, 2009.

20. Cao Y, Ho DD, Todd J, Kokka R, Urdea M, Lifson JD, Piatak M Jr, Chen S, Hahn BH, Saag MS, et al: Clinical evaluation of branched DNA signal amplification for quantifying HIV type 1 in human plasma. AIDS Res Hum Retroviruses 11: 353-361, 1995.

21. Liutkauskiene S, Janciauskiene R, Jureniene K, Grizas S, Malonyte R and Juozaityte E: Retrospective analysis of the impact of platinum dose reduction and chemotherapy delays on the outcomes of stage III ovarian cancer patients. BMC Cancer 15: 105, 2015.

22. Kohler C, Radpour R, Barekati Z, Asadollahi R, Bitzer J, Wight E, Bürki N, Diesch C, Holzgreve W and Zhong XY: Levels of plasma circulating cell free nuclear and mitochondrial DNA as potential biomarkers for breast tumors. Mol Cancer 8: $105,2009$.

23. Zane M, Agostini M, Enzo MV, Casal Ide E, Del Bianco P, Torresan F, Merante Boschin I, Pennelli G, Saccani A, Rubello D, et al: Circulating cell-free DNA, SLC5A8 and SLC26A4 hypermethylation, BRAF (V600E): A non-invasive tool panel for early detection of thyroid cancer. Biomed Pharmacother 67: 723-730, 2013.

24. Rass U: Resolving branched DNA intermediates with structure-specific nucleases during replication in eukaryotes. Chromosoma 122: 499-515, 2013.

25. Hao TB, Shi W, Shen XJ, Qi J, Wu XH, Wu Y, Tang YY and Ju SQ: Circulating cell-free DNA in serum as a biomarker for diagnosis and prognostic prediction of colorectal cancer. Br J Cancer 111: 1482-1489, 2014.

26. Beiter T, Fragasso A, Hudemann J, Niess AM and Simon P: Short-term treadmill running as a model for studying cell-free DNA kinetics in vivo. Clin Chem 57: 633-666, 2011. 